\title{
THERMOVISCOUS REMAGNETIZATION IN SOME APPALACHIAN LIMESTONES
}

\author{
Dennis V. Kent
}

Lamont-Doherty Geological Observatory and Department of Geological Sciences, Columbia University

\begin{abstract}
Experimental evidence shows that blocking temperature-relaxation time theory for single-domain magnetite can grossly underestimate laboratory thermal demagnetization temperatures of a present day viscous remanence in Devonian 1imestones of New York State. Thermoviscous remagnetization at moderately elevated burial temperatures during the late $\mathrm{Paleozoic}$ cannot therefore be readily excluded for the origin of the stable secondary component in these rocks. More generally, these results emphasize that sing le domain thermal activation theory cannot be assumed a priori to correctly predict temperature of thermoviscous remanence acquisition in all magnet ite-bearing rocks.
\end{abstract}

\section{The Problem}

It is now quite clear that lower (Helderberg) and middle (e.g., Onondaga) Devonian limestones in New York State have been completely remagnetized in the late Paleozoic [Kent, 1979; Scotese et a1., 1982]. The origin of the stable secondary magnetization in these rocks is however less apparent. Quite pure magnetite (Curie point $570^{\circ} \mathrm{C}$, lattice parameter $8.395 \mathrm{~A}$ ) in spheroidal and botryoidal forms is reported by McCabe et al. [1983] as common in some of these limestones. These authors propose that the secondary magnetization is a chemical remanence due to authigenic growth of magnetite; the possibility that the stable secondary component is due to thermal remagnetization of pre-existing magnetite was discarded because the observed laboratory demagnetization temperatures are higher than predicted using published estimates of burial temperature history.

To illustrate the relevant factors in this problem, detailed thermal demagnetization diagrams are shown in Figure 1 for typical limestone samples collected in parts of New York State with different burial temperature histories as indicated by the conodont alteration index (CAI) isograds of Harris et al. [1978]. The CAI values can range from 1 to 5 , indicating low to high thermal alteration. The sample of Onondaga Limestone (Figure la) was taken in the CAI 4 zone. Two components of magnetization of about equal importance are observed to contribute to the natural remanent magnetization (NRM). A norther$1 y$ and steeply down magnetization (component A) is the first to be removed, over progressive demagnetization temperatures ranging up to $275^{\circ} \mathrm{C}$. Further heating ( 45 minutes each step) shows the removal of a final southeasterly and shallow up vector (component $B$ ) until the NRM is reduced to less than $1 \%$ of its original magnitude by $500^{\circ} \mathrm{C}$.

Copyright 1985 by the American Geophysical Union.

Paper number $5 \mathrm{L6692.}$

0094-8276/85/005L-6692\$03.00
Virtually identical demagnetization behavior can be seen in the upper Silurian Cayugan dolomite collected near the CAI 3 isograd, and lower Devonian Helderberg limestone from the CAI 4 zone (Figure 4 of Scotese et a 1. [1983]).

Samples of Tully Limestone (upper middle Devonian) were taken from farther west in New York, in the CAI 2 zone. The same $A$ and $B$ components are both usually present (Figure lb). However, here $B$ is of much smaller magnitude relative to $A$, typically accounting for less than $5 \%$ of the NRM but present to demagnetization levels of at least $475^{\circ} \mathrm{C}$. Onondaga limestone samples also collected in the CAI 2 zone of western New York show these same thermal demagnetization characteristics (Figure 5b, c, d in Kent [1979]). That study moreover shows that the total blocking temperature distribution inferred from saturation remanence does not vary appreciably in the Onondaga across CAI isograds ranging from 2 to 4 . This suggests that differences in bulk magnetic properties are not responsible for the apparently systematically different relative contributions of the $A$ and $B$ components in the NRM of Helderberg and middle Devonian limestones in western and eastern New York.

At issue is the origin of component B. The mean direction of $B$ in samples of the Helderberg, Onondaga and Tully limestones studied here from 18 sampling sites is $D=166.5^{\circ}, I=-10.4^{\circ}, k=86$, a $95=3.8^{\circ}$, practically the same as the mean direction of the Helderberg $\left(D=165^{\circ}, I=-10^{\circ}\right)$ reported by Scotese et a1. [1983]. After correction for the non-horizontal bedding tilts at the eastern New York sampling sites, $k$ is reduced to 12 and the fold test is therefore negative at the $99 \%$ confidence level. On the basis of its direction, uniform reverse polarity and post-folding origin, the $B$ component most likely was acquired sometime during the ca. 70 My long Kiaman Reverse Interval which ended in the late Permian about $250 \mathrm{Ma}$.

McCabe et a1. [1983] point out that even with CAI $4.5\left(255^{\circ} \mathrm{C}\right.$ for $10^{8}$ years), maximum demagnetization temperatures of about $400^{\circ} \mathrm{C}$ predicted from the time-temperature diagram of Pullaiah et al. [1975] fall short of explaining the observed laboratory demagnetization temperatures of up to $5000 \mathrm{C}$ for what is referred to here as the $B$ component. But if the $A$ component (mean $D=354.10, I=69.70, k=68, a 95=4.40$ ) is as sumed to be a viscous remanent magnetization (VRM) acquired at ambient temperatures $(200 \mathrm{C})$ since the beginning of the Brunhes Normal Polarity Chron $(0.73 \mathrm{Ma})$, then this theoretical time-temperature relationship also cannot account for the A component because the maximum demagnetization temperature predicted (1500) is far less than that observed (275-3000C).

\section{Drumlin Test}

To exclude the possibility that the A component was acquired over an unexpectedly long time 


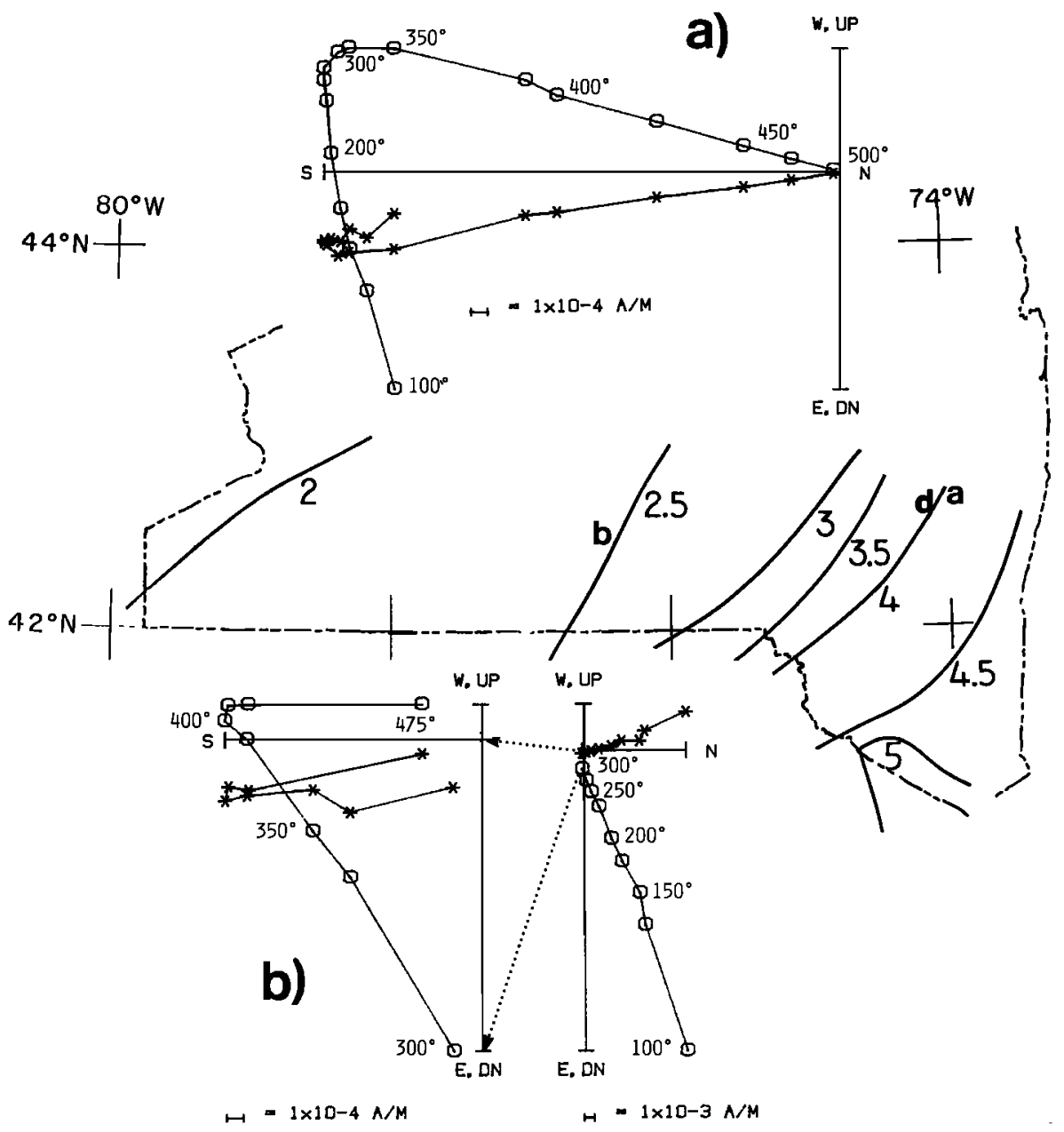

Fig. 1. Sketch map of New York State with CAI isograds for Silurian to middle Devonian rocks [Harris et a1., 1978]. Orthogonal plots of NRM thermal demagnetization (open circles on vertical and stars on horizontal axes) for a) sample C4 of Onondaga limestone, and b) sample DTA 2 of Tully Limestone in two parts to show detail near the origin. Sampling localities indicated on map for sample C4 by letter 'a', for sample DTA 2 by 'b', and for drumlins discussed in text by 'd'.

period (e.g., during the 34 My Cretaceous Long Norma1), a "drumlin test" was performed. Oriented samples were collected from 8 limestone cobbles in two late Pleistocene drumlin deposits near Berne, N.Y. The limestone cobbles (several of which contain Devonian brachiopod fossils) were most likely transported by glaciers from exposures of the Helderberg and Onondaga about 2 $\mathrm{km}$ to the north. Thermal demagnetization of the limestone cobbles reveals two components of magnetization (Figure 2a). A higher temperature ( 3000 to $4750 \mathrm{C}$ ) component is we 11 defined within each sample but is randomly oriented from sample to sample (Figure 2b), giving a positive conglomerate test. This component most probably corresponds to the stable $B$ component of the in situ limestones. The lower temperature component in contrast is grouped near the present field direction (Figure 2c) and persists to unexpectedly high demagnetization temperatures of about $275^{\circ} \mathrm{C}$. This component is clearly a recently acquired VRM and by implication so is the A component of the in situ limestones. Now however there is even wider disagreement with the relaxation time-blocking temperature theoretical curves of Pullaiah et al. [1975] because the permissible acquisition time of the VRM has been reduced to about 10,000 years (Figure 3 ).

Confirmation of the time-temperature trends derived from the drumlin results was obtained by an elevated-temperature VRM acquisition experiment (2500C for 3 weeks in $0.056 \mathrm{mT}$ ) on a thermally demagnetized limestone cobble sample. The demagnetization temperature required to remove $95 \%$ of this VRM was $3500 \mathrm{C}$, broadly parallel in trend with the removal temperature of the longterm ambient temperature VRM in the drumlin test.

\section{Time-temperature Relations}

These data show that thermal activation is considerably more potent than the theory used by Pullaiah et al. [1975] allows. These authors already noted wide discrepancies of the same sense in their experimental work and suspected magnetochemical alteration as a contributing factor. However, little indication of such alteration effects are seen here, particularly for the drumlin deposits.

Walton [1980] developed a thermal activation 


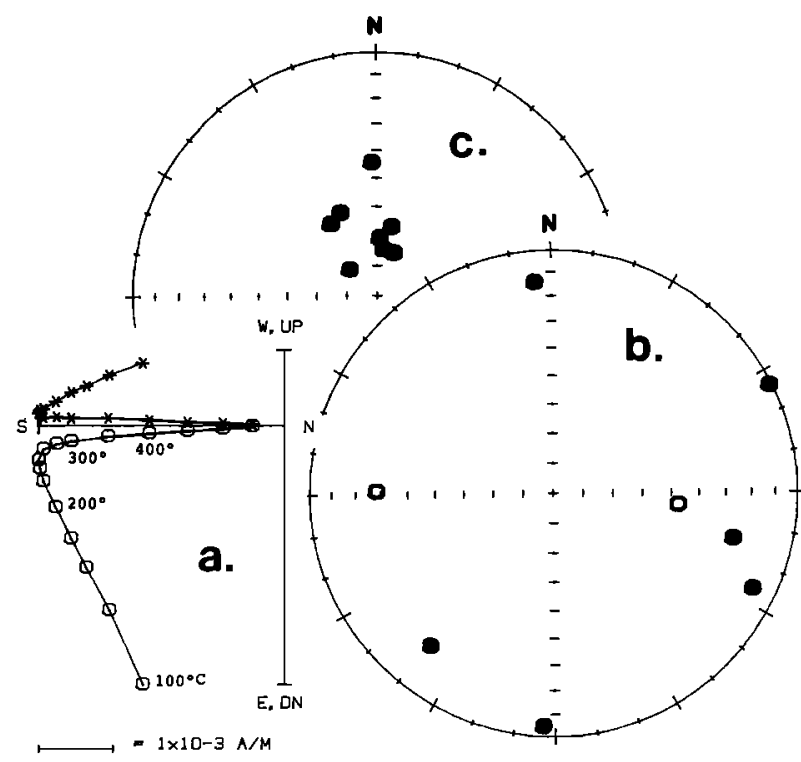

Fig. 2. Paleomagnetic data for 8 limestone cobbles in drumlins. a) Representative orthogonal plot of NRM thermal demagnetization. Isolated directions of high temperature $B$ component (b) and of low temperature $A$ component $(c)$, with filled (open) circles plotted on lower (upper) hemispheres of equal-area projections.

theory which includes a dependence on grain size distribution. Middleton and Schmidt [1982] calculated relaxation time-blocking temperature curves for magnetite from this theory assuming a log normal distribution of grain size. The drumlin test data are seen to be in better agreement with the predictions of this version of Walton's theory (Figure 3). For example, a VRM acquired at 20 ac for 10,000 years should be removed by heating for 45 minutes to $2400 \mathrm{C}$, about 1000 higher than predicted by the diagram of Pullaiah et al. [1975] and closer to the observed laboratory demagnetization temperature of $275^{\circ}$ for the drumlin A component.

Given the approximate agreement of the $A$ component data with Middleton and Schmidt's version of Walton's theory, it might be of interest to reconsider the origin of the limestone $B$ component using these relations as a guide. For the extreme case also considered by $\mathrm{McCabe}$ et $\mathrm{al}$. [1983], exposure to a temperature of $255^{\circ} \mathrm{C}$ for 108 years (corresponding to CAI 4.5) should activate magnetizations which require a laboratory demagnetization temperature of about $4800 \mathrm{C}$, now much $c$ loser to the observed maximum thermal demagnetization value for the $B$ component. However, for the other end of the applicable temperature history spectrum corresponding to CAI 2 ( $1000 \mathrm{C}$ for $10^{8}$ years), a laboratory demagnetization temperature of on $1 y$ about $3750 \mathrm{C}$ is predicted, about $1000 \mathrm{C}$ below that observed in the western New York sites.

\section{Discussion}

It is evident that thermal remagnetization cannot be readily dismissed as a mechanism to account for the secondary $B$ component magnetization in upper Silurian and lower to middle Devo- nian limestones in the eastern part of New York State where the CAI is 4 and greater. Preexisting magnetite, perhapa formed authigenically but at an earlier stage, would be needed to carry the Permian thermally remagnetized B component. Magnetite of pre-tectonic origin would also be compatible with the structure-controlled magnetic fabrics observed in the folded Onondaga Limestone in eastern New York [Graham, 1967; Kent, 1979].

Although of very diminished relative magnitude in the western New York sites, the B component where resolvable also extends to laboratory demagnetization temperatures of around $4750 \mathrm{C}$. Because of the low burial temperatures indicated by conondont alteration in western New York, the B component there is less obviously accounted for by thermal remagnetization.

A chemical remanence might therefore be considered as the acquisition mechanism for this magnetization in the low CAI areas of New York, even though there is little expression of varying degrees of chemical growth of magnetite in the bulk magnetic properties of the limestones. Alternatively, the strict application of singledomain thermal activation theory in general is more likely to be inappropriate for these rocks.

McCabe et a1. [1983] describe the magnetite crystal aggregates in the Helderberg extracts as ranging in size from 3 to 20 micrometers in diameter. Individual crystallites are from 0.5 to 2 micrometers in diameter, still well above the nominal critical single domain size (.05 micrometers). Supporting indications of larger sized, multidomain magnetite are coarse-grain trends obtained in Lowrie-Fuller tests on the Onondaga Limestone and the fact that the maximum unblocking temperature of NRM (or saturation IRM) is depressed by $600 \mathrm{C}$ or more below the Curie

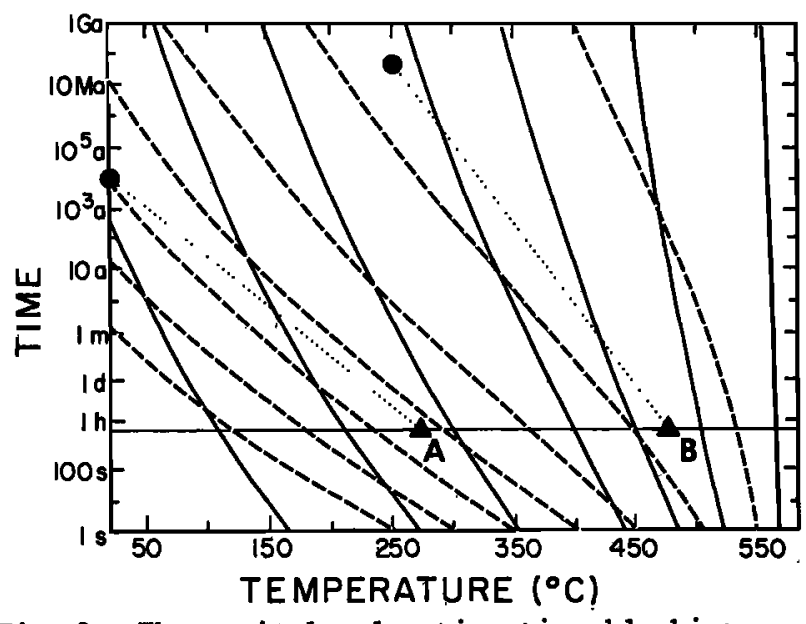

Fig. 3. Theoretical relaxation time-blocking temperature relations for magnetite, solid curves from Pullaiah et al. [1975] and dashed curves from Middleton and Schmidt [1982]. Triangles are the laboratory demagnetization conditions required to remove the $A$ and the $B$ components of NRM in the limestones. Filled circles are the inferred time-temperature conditions of acquisition assuming a thermoviscous origin (constraints on component $A$ from drumlin test, constraints on component $B$ assuming burial temperature corresponding to CAI 4.5). 
point of magnetite [Kent, 1979]. As pointed out by Dunlop [1983], if (thermo)viscous remanence involves multidomain wall activation phenomenon, there may be a broad thermal demagnetization tail extending from about the values given by single domain equations to much higher temperatures. If this effect, for which Dunlop [1983] cites experimental evidence, is applicable in the limestones of New York State, then there is the interesting possibility that the relatively small $B$ component found in the western New York sites represents just the extended blocking temperature tail of a low temperature viscous remanence. The existence of such a tail might also explain why the very dominant present-day VRM (A component) can be observed to laboratory demagnetization temperatures as high as $4000 \mathrm{C}$ in the western New York sites (Figure 1b). Such elevated demagnetization temperatures for a VRM are well beyond values predicted from single-domain theory.

In conclusion, a thermoviscous origin for the secondary magnetizations in these limestones is permissible, given the demonstrated large uncertainty in applicability of magnetic relaxation time-blocking temperature theoretical relationships. Meaningful assessment of more complex remagnetization mechanisms, such as thermochemical that could be due to the migration of hot fluids, clearly will depend on the development of a more realistic theory so that the inevitable thermoviscous contribution can be properly evaluated. Indications from the present study are that the importance of thermoviscous effects in magnetite-bearing rocks has tended to be underestimated in low to moderate temperature regimes. A resultant problem that is raised and worth further investigation concerns the generality of the expression relating magnetic and isotopic blocking processes [York, 1978].

Acknowledgments. A. Kent and C. Kent are thanked for field assistance, J. E. Sanders for guiding us to suitable drumlin localities, and $S$. Halgedahl and $J$. Miller for critical comments. Supported by NSF (EAR85-07046). LDGO \$3893.

\section{References}

Dunlop, D. J., Viscous magnetization of 0.04-100 um magnetites, Geophys. J. R. astr. Soc.s 74 , $667-687,1983$.
Graham, J. W., Significance of magnetic anisotropy in Appalachian sedimentary rocks, Am. Geophys. Union Mon. 10, 627-648, 1967.

Harris, A. G., L. D. Harris, and J. B. Epstein, $0 i 1$ and gas data from Paleozoic rocks in the Appalachian Basin: maps for assessing hydrocarbon potential and therma 1 maturity (conodont color alteration isograds and overburden is opachs), U.S. Geo1. Surv. Misc. Invest. Series, 1978 .

Kent, D. V., Paleomagnetism of the Devonian Onondaga Limestone revisited, J. Geophys. Res.. 84, 3576-3588, 1979.

McCabe, C., R. Van der Voo, D. R. Peacor, C. R. Scotese, and R. Freeman, Diagenetic magnetite carries ancient yet secondary remanence in some $\mathrm{Paleozoic}$ sedimentary carbonates, Geology, 11, 221-223, 1983.

Middleton, M. F., and P.W. Schmidt, Paleothermometry of the Sydney Basin, J. Geophys. Res.. 87, 5351-5359, 1982.

Pullaiah, G., E. Irving, K. L. Buchan, and D. J. Dunlop, Magnetization changes caused by buria 1 and up lift, Earth Planet. Sci, Lett.. 28, 133$143,1975$.

Scotese, C. R., R. Van der Voo, and C. McCabe, Paleomagnetism of the Upper Silurian and Lower Devonian carbonates of New York State: evidence for secondary magnetizations residing in magnetite, Phys, Earth Planet. Inter.. 30, 385-395, 1982 .

Walton, D., Time-temperature relations in the magnetization of assemblies of single domain grains, Nature, 286, 245-247, 1980.

York, D., A formula describing both magnetic and isotopic blocking temperatures, Earth Planet. Sci. Lett. . 39, 89-93, 1978.

D. V. Kent, Lamont-Doherty Geological Observatory, Palisades, NY 10964.

(Received September 3, 1985; accepted October 3,1985 ) 